\title{
Article \\ Buckling Electrothermal NEMS Actuators: Analytic Design for Very Slender Beams
}

\author{
Richard Syms* *il and Dixi Liu
}

Citation: Syms, R.; Liu, D. Buckling Electrothermal NEMS Actuators: Analytic Design for Very Slender Beams. Micro 2022, 2, 54-67. https://doi.org/10.3390/ micro2010003

Received: 20 December 2021 Accepted: 10 January 2022

Published: 13 January 2022

Publisher's Note: MDPI stays neutral with regard to jurisdictional claims in published maps and institutional affiliations.

Copyright: () 2022 by the authors Licensee MDPI, Basel, Switzerland. This article is an open access article distributed under the terms and conditions of the Creative Commons Attribution (CC BY) license (https:// creativecommons.org/licenses/by/ $4.0 /)$.

\author{
Department of Electrical and Electronic Engineering, Imperial College London, Exhibition Road, \\ London SW7 2AZ, UK; xixi198905@gmail.com \\ * Correspondence: r.syms@imperial.ac.uk
}

\begin{abstract}
Analytic approximations are presented for the response of buckling-mode electrothermal actuators with very slender beams with a width-to-length ratio of $W / L \leq 0.001$ of the type found in nanoelectromechanical systems (NEMS). The results are found as closed-form solutions to the Euler beam bending theory rather than by an iterative numerical solution or a time-consuming finite element analysis. Expressions for transverse deflections and stiffness are presented for actuators with the common raised cosine and chevron pre-buckled shapes. The approximations are valid when the effects of bending dominate over those of axial compression. A few higher-order approximations are also presented for less slender beams with $0.001 \leq W / L \leq 0.01$.
\end{abstract}

Keywords: electrothermal actuator; beam buckling; MEMS; NEMS

\section{Introduction}

Electrothermal actuators are widely used in microelectromechanical systems (MEMS) because a device with in-plane motion may be constructed simply by etching and undercutting a mechanical layer to form a suspended structure that is heated by passing a current between the anchors [1]. The most common arrangements are shape bimorph [2,3] and buckling [4-6] actuators. Here, we focus on the latter, which have the general arrangement as shown in Figure 1a. Here, an array of beams is supported on anchors at either end. The beams are pre-buckled to force motion in the direction shown, tied together with a crossbeam at their midpoint to ensure collective motion, and driven by constrained thermal expansion.

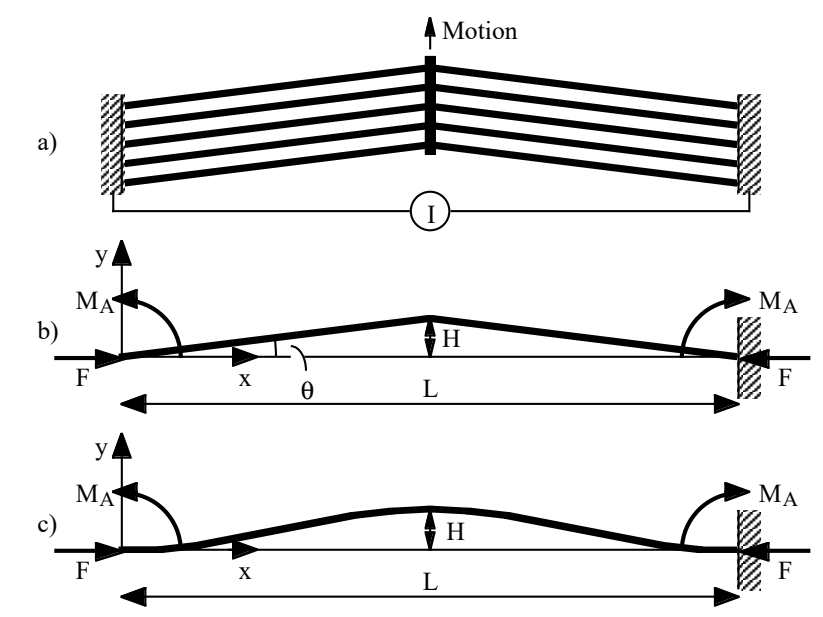

Figure 1. (a) Buckling electrothermal actuator; $(\mathbf{b}, \mathbf{c})$ chevron and raised cosine pre-buckle.

If the beams are initially shaped into a chevron layout, the device is known as a V-beam actuator. The basis of actuation has been investigated using the Euler buckling theory and a 
finite element analysis [7,8], typically using the simplified single-beam model in Figure $1 \mathrm{~b}$. More recently, geometry effects [9], non-linearity [10], and dynamics [11,12] have been investigated, and there have been continuing attempts to improve the FEM analysis [13-16]. An alternative layout is the raised cosine pre-buckle in Figure 1c, which has been extensively analysed under the conditions leading to snap-through and bistability [17-19]. The thermal aspects of buckling actuators have also been modelled $[20,21]$, and a new designthe Z-shaped actuator, which uses a stepped beam layout-has been developed [22-24]. More complex arrangements have been developed, including cascaded [7,25-29] and outof-plane [30] actuators as well as actuators with a variable beam width [31,32], built-in strain gauges [33], and feedback control [34,35]. V-beam actuators have been used as the basis of linear [36-38] and rotary [36,39] stepping motors. Applications include electrical switches [40,41], optical alignment systems [42-45], tunable or scanning micro-optical devices [46-48], devices for cell manipulation [49-51], and movable neural microelectrode arrays [52,53]. The devices and applications are reviewed in [54].

Despite approximately twenty years of research, a few difficulties remain. Neither the analytic nor the finite element models of elastic deformation are very satisfactory. The former does not yield closed-form expressions and the latter requires excessive computation when the beams are very long and narrow and the number of elements is large. Apart from an analytic approximation for the deflection in [6], derived from purely geometric arguments, there are no closed-form design formulas so layouts are often chosen on an ad hoc basis. The aim of this paper is to remedy this deficiency by developing approximations to buckling theory that provide closed-form solutions. The solutions are valid for very slender beams with a width-to-length ratio in the approximate range of $W / L \leq 0.001$ when bending dominates over axial compression; nanoelectromechanical systems (NEMS) actuators of this type capable of micron-scale deflections have been demonstrated by sidewall transfer lithography [55]. Raised cosine actuators and actuators with a chevron pre-buckle are analysed and discussed in Section 2. Additional results including alternative approximations, intrinsic stress, the relation between deflection and power, and transverse stiffness are considered in Section 3. Conclusions are drawn in Section 4.

\section{Methods}

We started by considering the raised cosine pre-buckle but followed the general approach used for V-beam actuators in [7]. We assumed a single beam with the shape shown in Figure 1c; the performance of the beam arrays could be estimated by scaling. The beam had a length $L$ and central offset $H$, a rectangular cross-section with an in-plane width $W$ and depth $D$, and was built-in at both ends. Its initial shape was:

$$
y_{0}(x)=H \sin ^{2}\left(\frac{\pi x}{L}\right) .
$$

Forces $F$ and moments $M_{A}$ modelled the effects of the anchors and the shape $y(x)$ of the loaded beam could be found by solving the Euler buckling equation [56]:

$$
E I \frac{d^{2}\left(y-y_{0}\right)}{d x^{2}}=M(x) .
$$

Here, $M(x)=M_{A}-F y$ is the bending moment, $I=W^{3} D / 12$ is the second moment of the area of the beam, and $E$ is the Young's modulus for the material used. An approximation implicit in the above was the replacement of the change in the beam curvature by the second derivative, which could clearly render the result inaccurate for a large pre-buckle or deflection. The analysis was best carried out by substituting $y=y_{0}+u$, which yielded:

$$
\frac{d^{2} u}{d x^{2}}+\left(\frac{F}{E I}\right) u=\left(\frac{M_{A}}{E I}\right)-\left(\frac{F}{E I}\right) y_{0}
$$


Equation (3) may be solved in terms of a particular integral and a complementary function. Applying the boundary conditions $u=\frac{d u}{d x}=0$ at $x=0$ and $x=L$, the result was:

$$
u(x)=H\left\{\frac{k^{2} L^{2}}{4 \pi^{2}-k^{2} L^{2}}\right\} \sin ^{2}\left(\frac{\pi x}{L}\right) .
$$

Here, $k=\sqrt{F / E I}$. This result demonstrated a special quality of the raised cosine pre-buckle: the deflected shape did not change. The midpoint deflection $U=u(L / 2)$ was:

$$
U=H\left\{\frac{k^{2} L^{2}}{4 \pi^{2}-k^{2} L^{2}}\right\}
$$

Equation (5) implies that $U$ would be infinite when $k L=2 \pi$, the Euler buckling condition. Integrating the deflected beam shape allowed the change in length $\Delta L$ due to bending to be found as $\Delta L=\delta L-\delta L_{0}$, where we made the standard approximation $\delta L=1 / 2 \int_{0}^{L}\left(\frac{d y}{d x}\right)^{2} d x$; $\delta L_{0}$ was the integral in the unloaded case (see, e.g., [9]). Integration gave:

$$
\frac{\Delta L}{L}=\left(\frac{\pi^{2} H^{2}}{4 L^{2}}\right)\left\{\frac{k^{2} L^{2}\left(8 \pi^{2}-k^{2} L^{2}\right)}{\left(4 \pi^{2}-k^{2} L^{2}\right)^{2}}\right\} .
$$

The force $F$ was derived from the constrained thermal expansion. Assuming an average temperature rise $\Delta T_{a v g}$, the beam must satisfy a compatibility condition [7]:

$$
\frac{F}{E W D}=\alpha \Delta T_{a v g}-\frac{\Delta L}{L} .
$$

Here, $\alpha$ is the linear thermal expansion coefficient of the beam material. The three terms in Equation (7) describe the changes in the length due to the axial compression, thermal expansion, and bending, respectively. This equation can also be written in the form:

$$
\alpha \Delta T_{a v g}=\frac{\Delta L}{L}+\left(\frac{W}{L}\right)^{2}\left(\frac{k^{2} L^{2}}{12}\right) .
$$

Equations (6) and (8) allowed $\Delta T_{a v g}$ to be found as a function of $k L$. As $U$ is also a function of $k L$, it could be plotted as a function of $\Delta T_{a v g}$. Alternatively, these coupled equations could be solved iteratively. For example, Figure 2 shows the variation of $U$ with $\Delta T_{a v g}$ for a silicon beam with the following parameters: $E=170 \times 10^{9} \mathrm{Nm}^{-2}, \alpha=2.6 \times 10^{-6} \mathrm{~K}^{-1}$, $L=1 \mathrm{~mm}, H=5 \mu \mathrm{m}, D=5 \mu \mathrm{m}$, and values of $W$ ranging from $20 \mu \mathrm{m}$ (MEMS domain) to $0.1 \mu \mathrm{m}$ (NEMS). In each case, the variation was similar. When the temperature rise $\Delta T_{\text {avg }}$ was negative (so the beam was artificially cooled and under tension), $U$ was negative and tended to $-H$, straightening the beam. When $\Delta T_{a v g}$ was positive (so the beam was under compression), the deflection rose monotonically as the beam buckled. For values of $W>1 \mu \mathrm{m}$, the variations differed; however, for $W \leq 1 \mu \mathrm{m}$, the analytic solutions all tended to one another. Note, however, that for very large deflections, the approximation of the curvature changes by a second derivative in Equation (2) would no longer be valid.

Similar calculations were carried out using the commercial FEA solver, COMSOL ${ }^{\circledR}$ Multiphysics 4.4. A 2D model of a beam with a raised cosine pre-buckle and the dimensions above was built in the $x-y$ plane. The heat transfer module was used to apply a temperature change and the solid mechanics module to apply boundary constraints. Structural and thermal physics were coupled by thermal expansion in the multiphysics modelling interface. The plane stress approximation was used to eliminate the out-of-plane components of the stress tensor, and a stationary study was carried out using a geometrically non-linear analysis. The number of iterations was set to 50 , with the solver automatically determining the damping factor for Newton's method. In addition to the previous parameters, a Poisson's ratio of $v=0.28$ was assumed. The discrete points in Figure 2 show the results 
for the four largest beam widths. The results were in good agreement with the analytic model for $W=20 \mu \mathrm{m}$ and $W=10 \mu \mathrm{m}$ but diverged for $W=5 \mu \mathrm{m}$ and $W=1 \mu \mathrm{m}$; for smaller values of $W$, convergence was not reached after 50 iterations.

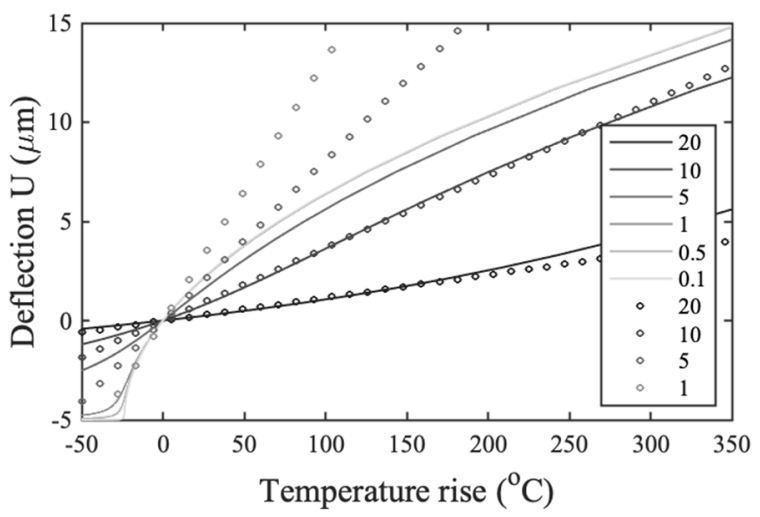

Figure 2. Variation of deflection with average temperature rise for a raised cosine actuator, with $E=170 \times 10^{9} \mathrm{Nm}^{-2}, \alpha=2.6 \times 10^{-6} \mathrm{~K}^{-1}, L=1 \mathrm{~mm}, H=5 \mu \mathrm{m}, D=5 \mu \mathrm{m}$, and different values of $W$ in microns. Full lines show the analytic theory; points show the results from the FEA.

A further difficulty was the increase in memory and run time as the $W / L$ decreased. Table 1 shows the requirements for 37 temperature values using an Intel ${ }^{\circledR}$ Core $^{\mathrm{TM}} \mathrm{i} 7-2600$ processor with a $3.4 \mathrm{GHz}$ clock speed and $16 \mathrm{~Gb}$ RAM. The increase in the computation resource implied that the problem would rapidly become intractable, and these problems would worsen in 3D.

Table 1. Memory requirements and solution time for the finite element analysis models.

\begin{tabular}{cccc}
\hline Beam Width $(\boldsymbol{\mu m})$ & Physical Memory $(\mathbf{G b})$ & Virtual Memory $(\mathrm{Gb})$ & Run Time $(\mathbf{s})$ \\
\hline 20 & 1.23 & 1.32 & 155 \\
\hline 10 & 1.37 & 1.49 & 342 \\
\hline 5 & 1.72 & 1.86 & 816 \\
\hline 1 & 4.37 & 4.69 & 5955 \\
\hline
\end{tabular}

Although complete, the analytic solution above was still unsatisfactory because it required a numerical evaluation. A closed-form solution for $U$ in terms of $\Delta T_{\text {avg }}$ could allow the performance to be estimated directly from the geometric parameters. We obtained such a solution by first comparing Equations (5) and (6). It is simple to show that:

$$
U^{2}+2 H U=\left(\frac{4 L^{2}}{\pi^{2}}\right) \frac{\Delta L}{L} .
$$

For slender beams with $W / L \ll 1$, we neglected the second term on the right-hand side of Equation (8), effectively neglecting the effects of axial compression. In this case, $\Delta L / L=\alpha \Delta T_{a v g}$, and Equation (9) approximated to the quadratic:

$$
U^{2}+2 H U-\frac{4 \alpha \Delta T_{a v g} L^{2}}{\pi^{2}}=0 .
$$

Equation (10) had two solutions. Retaining only the positive solution, the following expression for the deflection could be obtained:

$$
U=H\left\{\sqrt{1+\frac{4 \alpha \Delta T_{a v g} L^{2}}{\pi^{2} H^{2}}}-1\right\} .
$$


Equation (11) was the desired closed-form solution. It yielded a real result even when $\Delta T_{\text {avg }}$ was negative until $\Delta T_{a v g}=-\pi^{2} H^{2} / 4 \alpha L^{2}$. Figure 3 compares the exact (axial stress included) and approximate (axial stress ignored) variation of the deflection with the average temperature rise for the same parameters as Figure 2 but with only the smallest beam width $\left(W=0.1 \mu \mathrm{m}\right.$, for which $\left.W / L=10^{-4}\right)$. The agreement was excellent and the closed-form analytic formula tracked the exact solution closely, even when the deflection was large. Other curves are superimposed on this figure; these are discussed later.

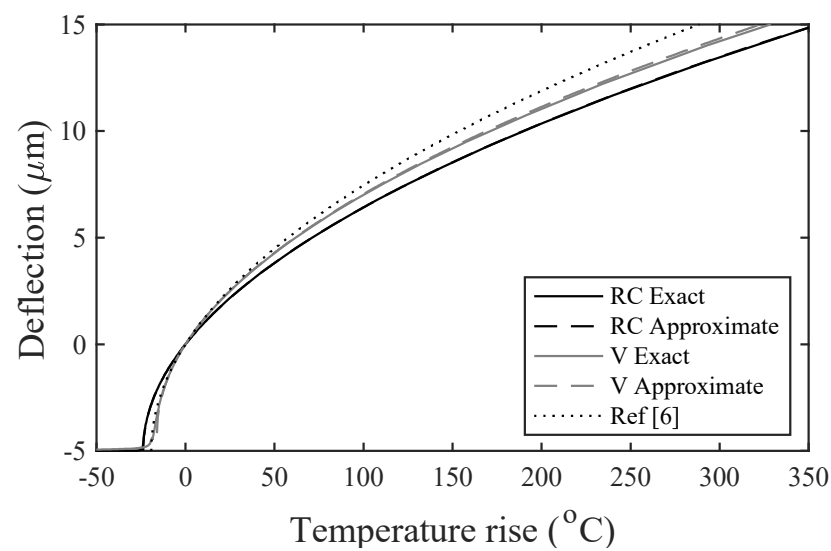

Figure 3. Comparison of the exact and approximate variations of deflection with the average temperature rise for raised cosine (RC) and V-beam actuators (V), with $E=170 \times 10^{9} \mathrm{Nm}^{-2}$, $\alpha=2.6 \times 10^{-6} \mathrm{~K}^{-1}, L=1 \mathrm{~mm}, H=5 \mu \mathrm{m}, D=5 \mu \mathrm{m}$, and $W=0.1 \mu \mathrm{m}$. Also shown are the predictions of [6].

We repeated the analysis for the V-beam actuator shown in Figure $1 \mathrm{~b}$. The beam had a length $L$ and tilt angle $\theta$ so the central offset was $H=\left(\frac{L}{2}\right) \tan (\theta)$. As $y_{0}$ is a linear function of $x$ for $0 \leq x \leq L / 2$, Equation (2) could be written as $\frac{d^{2} y}{d x^{2}}+\left(\frac{F}{E I}\right) y=\frac{M_{A}}{E I}$ in this range. The boundary conditions were $y=0$ at $x=0$ and $\frac{d y}{d x}=\tan (\theta)$ at $x=0$ and $x=L / 2$. The solution was [7]:

$$
y(x)=\frac{\tan (\theta)}{k}\left\{\sin (k x)+\tan \left(\frac{k L}{4}\right)\{1-\cos (k x)\}\right\} .
$$

This result implied that the beam changed shape significantly as it deflected, in contrast to the raised cosine actuator. The maximum deflection was $U=\left.\left(y-y_{0}\right)\right|_{L / 2}$ or:

$$
U=\frac{2 \tan (\theta)}{k}\left\{\tan \left(\frac{k L}{4}\right)-\frac{k L}{4}\right\} .
$$

Integrating the deflected beam shape again allowed the change in the length $\Delta L$ due to bending to be found. The result was [7]:

$$
\frac{\Delta L}{L}=\frac{\tan ^{2}(\theta)}{4 k L}\left\{2 G[1-\cos (k L)]+\left(1-G^{2}\right)[\sin (k L)-k L]\right\} .
$$

Here, $G=\tan \left(\frac{k L}{4}\right)$. The compatibility equation was as before, and Equations (14) and (8) then allowed $\Delta T_{\text {avg }}$ to be found as a function of $k L$. As Equation (13) was also a function of $k L$, $U$ could again be plotted in terms of $\Delta T_{\text {avg }}$. The results are superimposed on Figure 3 for the same parameters as before. The deflections were very similar to the variations obtained for the raised cosine actuator, suggesting that the deflection in the V-beam actuator was dominated by the excitation of the lowest-order buckling-mode. The results obtained using COMSOL (not shown) again agreed well but suffered from an even worse scaling of run times with $W / L$. 
The use of the very slender beam approach-relating $U$ to $\Delta L / L$ and then solving an approximate compatibility equation - could yield again an analytic approximation. This time, there were difficulties caused by the trigonometric functions in Equations (13) and (14). However, these could be circumvented using power series approximations. For example, substituting $\lambda=k L / 4$ allowed Equation (13) to be written as $\frac{U}{L}=\tan (\theta) f(\lambda)$, where:

$$
f(\lambda)=\frac{\tan (\lambda)-\lambda}{2 \lambda}
$$

As $\tan (x)=x+\frac{x^{3}}{3}+\frac{2 x^{5}}{15} \ldots$, we could approximate $f$ to order $\lambda^{4}$ as:

$$
f_{4}(\lambda)=\frac{\lambda^{2}}{6}+\frac{2 \lambda^{4}}{30}
$$

In a similar way, Equation (14) could be written as $\frac{\Delta L}{L}=\tan ^{2}(\theta) g(\lambda)$, where:

$$
g(\lambda)=\frac{2 \tan (\lambda)[1-\cos (4 \lambda)]+\left[1-\tan ^{2}(\lambda)\right][\sin (4 \lambda)-4 \lambda]}{16 \lambda} .
$$

To simplify the above, we first noted that:

$$
2 \tan (\lambda)[1-\cos (4 \lambda)]+\left[1-\tan ^{2}(\lambda)\right] \sin (4 \lambda)=4 \tan (\lambda) .
$$

$g(\lambda)$ could then be written as:

$$
g(\lambda)=\frac{\tan (\lambda)-\lambda\left[1-\tan ^{2}(\lambda)\right]}{4 \lambda} .
$$

With $g$ in this form, we obtained a power series approximation to the order $\lambda^{4}$ as:

$$
g_{4}(\lambda)=\frac{\lambda^{2}}{3}+\frac{3 \lambda^{4}}{15}
$$

These simple approximations clearly had limited validity. Figure 4 compares the variations of $f, f_{4}, g$, and $g_{4}$ with $\lambda$; both approximations were accurate only up to $\lambda \approx 0.3 \pi$, well below the buckling condition (when $f$ and $g$ both became infinite).

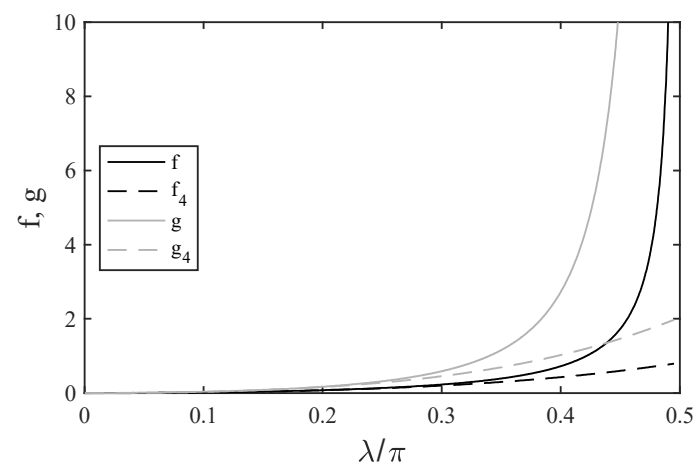

Figure 4. Comparison of the variations of the functions $f$ and $f_{4}$ and $g$ and $g_{4}$ with $\lambda$.

Despite this, they allowed useful closed-form solutions. For example, combining Equations (16) and (20), we obtained:

$$
g_{4} \approx 2 f_{4}+\frac{12 f_{4}^{2}}{5} .
$$


Rearranging, we obtained the quadratic equation:

$$
\frac{12 f_{4}^{2}}{5}+2 f_{4}-g_{4}=0 .
$$

Retaining only the positive root, we obtained:

$$
f_{4}=\frac{5}{12}\left\{\sqrt{1+\frac{12 g_{4}}{5}}-1\right\} .
$$

Noting the original definitions of $f$ and $g$, we then obtained the midpoint deflection $U$ as:

$$
U=\frac{5 L \tan (\theta)}{12}\left\{\sqrt{1+\frac{12 \Delta L}{5 L \tan ^{2}(\theta)}}-1\right\} .
$$

Neglecting the second term in the RHS of Equation (8) as before, we then obtained:

$$
U=\frac{5 L \tan (\theta)}{12}\left\{\sqrt{1+\frac{12 \alpha \Delta T_{\text {avg }}}{5 \tan ^{2}(\theta)}}-1\right\} .
$$

This result can, of course, be written in the alternative form:

$$
U=\frac{5 H}{6}\left\{\sqrt{1+\frac{3 \alpha \Delta T_{a v g} L^{2}}{5 H^{2}}}-1\right\} .
$$

Equation (26) was analogous to Equation (11) for the raised cosine pre-buckle. The predictions of this closed-form solution are superimposed on Figure 3 for the same parameters. Once again, there was a good agreement with the full model despite the apparent errors in $f_{4}$ and $g_{4}$. We constructed higher-order expansions of both functions and found that the expressions above gave good results despite their simplicity.

The performances of the two designs were clearly similar; however, the V-beam actuator gave a slightly larger deflection for a given temperature rise. Equations (11) and (26) could both be written in the form $U=A\left\{\sqrt{1+B \Delta T_{a v g}}-1\right\}$. Consequently, the initial sensitivity $S=d U /\left.d \Delta T_{\text {avg }}\right|_{0}$ of the deflection to temperature was $S=A B / 2$. For the two actuator types, the sensitivities $S_{R C}$ and $S_{V}$ were:

$$
S_{R C}=\frac{2 \alpha L^{2}}{\pi^{2} H} \quad S_{V}=\frac{\alpha L^{2}}{4 H} .
$$

Thus, the sensitivity was always proportional to $L^{2}$ and inversely proportional to $H$. For a common geometry, $S_{V} / S_{R C}=\pi^{2} / 8$, so the V-beam design was slightly more sensitive.

\section{Results}

In this section, we discuss several alternative results, power scaling laws and the related question of transverse stiffness. We started by considering the well-known formula for the deflection of a V-beam actuator derived in [6] by considering that the two beam sections remained straight and simply increased in length by an amount $\Delta L_{h}$ due to thermal expansion. Using a first-order approximation we obtained:

$$
U=\sqrt{L_{h}^{2}+2 L_{h} \Delta L_{h}-L_{h}^{2} \cos (\theta)}-L_{h} \sin (\theta) .
$$


Here, $L_{h}=L / 2$. Rearranging and substituting $H$ for $L_{h} \sin (\theta)$ and $\alpha \Delta T_{\text {avg }}$ for $\Delta L_{h} / L_{h}$ we obtained:

$$
U=H\left\{\sqrt{1+\frac{\alpha \Delta T_{a v g} L^{2}}{2 H^{2}}}-1\right\} .
$$

Equation (28) may also be written in the form $U=A\left\{\sqrt{1+B \Delta T_{\text {avg }}}-1\right\}$. Its predictions are also shown superimposed on Figure 3. It was clearly less accurate than Equation (26); however, the prediction was remarkable given that bending was entirely ignored.

We then considered alternative approximations for a raised cosine actuator that could be viable for less slender beams when the axial compression term in Equation (8) could not be neglected. Retaining this term, it was simple to show that Equation (10) becomes:

$$
U^{2}+2 H U-\left(\frac{4 L^{2}}{\pi^{2}}\right) \alpha \Delta T_{\text {avg }}=-\frac{4 W^{3} U}{3 U(H+U)} .
$$

Thus, a more exact relation between $U$ and $\Delta T_{a v g}$ was a cubic equation. Clearly, Equation (30) had a numerical solution. However, in the spirit of the present MS, where the focus is on solutions that yielded an insight, we derived an analytic approximation. We assumed that $U=U_{0}+U_{1}$, where $U_{0}$ was the solution to Equation (10) and $U_{1}$ was an additional perturbation. Substituting and neglecting the higher-order terms, it was simple to obtain:

$$
U_{1}=-\frac{2 W^{2} U_{0}}{3\left(H+U_{0}\right)^{2}}
$$

Thus, the effect of axial compression was to reduce the deflection by an amount that depended on $W$ and (for small deflections) was linearly proportional to $U_{0}$. Consequently, the initial slope of the deflection characteristic must reduce for wider beams. To illustrate this, Figure 5 compares the exact solution, the first approximation (11), and the second approximation (31). The parameters were as before, but the beam width $W$ was increased to $5 \mu \mathrm{m}$ (so that $W / L=5 \times 10^{-3}$ ). This width was sufficiently large that the first approximation was no longer valid. However, the second approximation was a good match to the exact solution except when $U_{0}$ tended to $-H$. This behaviour was to be expected from Equation (31); it is unimportant for practical applications when positive temperature rises are the norm.

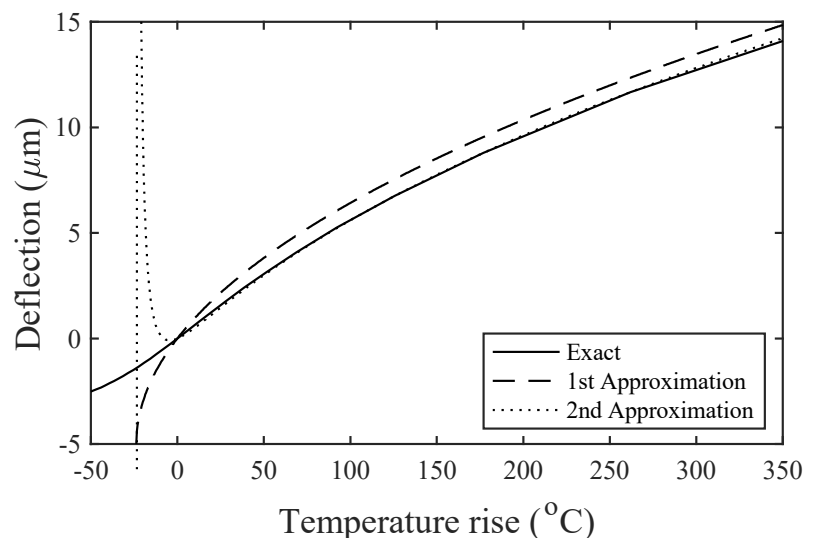

Figure 5. Comparison of the exact and two approximate variations of deflection with the average temperature rise for a raised cosine actuator with $E=170 \times 10^{9} \mathrm{Nm}^{-2}, \alpha=2.6 \times 10^{-6} \mathrm{~K}^{-1}$, $L=1 \mathrm{~mm}, H=5 \mu \mathrm{m}, D=5 \mu \mathrm{m}$, and $W=5 \mu \mathrm{m}$.

We noted that the addition of a tensile stress $\sigma$ (which could arise during processing) inserted an axial strain term $-\sigma / E$ into Equation (8). The intrinsic stress could, therefore, be included by replacing $\Delta T_{\text {avg }}$ with $\Delta T_{\text {avg }}-\sigma / E$ in the preceding expressions. The effect 
of stress was, therefore, to shift the deflection characteristics to the right. If measurements were made from the rest, the effect was to reduce the apparent deflection.

Finally, we considered the well-known relation between temperature and power (see, e.g., $[9,10])$. If the beam was heated by a power $P$ and cooled only by thermal conduction to the anchors, the steady-state temperature rise $\Delta T(x)$ was the solution to the heat conduction equation:

$$
k_{t h} W D \frac{d^{2} \Delta T}{d x^{2}}+\frac{P}{L}=0 .
$$

Here, $k_{t h}$ was the thermal conductivity of the beam material. The solution subject to the boundary conditions $\Delta T=0$ at $x=0$ and $x=L$ was:

$$
\Delta T(x)=\Delta T_{\max } \frac{4\left(x L-x^{2}\right)}{L^{2}} .
$$

Here, $\Delta T_{\max }$ was the temperature at $x=L / 2$. The average temperature could then be found by the integration of the temperature profile along the beam length as:

$$
\Delta T_{\text {avg }}=\frac{P L}{12 k_{t h} W D} .
$$

The previous expressions for deflection could be converted into variations with power by making this substitution; for an $N$-beam array, $P$ was simply divided by $N$. Similarly, for a device that was also cooled by gas conduction to the substrate, $P$ was multiplied by an efficiency term, $\eta$.

We then considered the transverse stiffness of a buckling actuator and showed how the slender beam approximation could be used to evaluate this quantity for the raised cosine type. Following previous authors [7], we assumed that the stiffness was found from the transverse force $F_{T}$ needed to return the midpoint deflection to zero. Unfortunately, the application of $F_{T}$ altered the axial force to a new value, $F^{\prime}$, and altered the end moment to $M^{\prime}{ }_{A}$. At a certain point, the rising transverse force will lead to snap-through [9], so the analysis was carried out with caution. To find the deflection $u \prime(x)$, we solved:

$$
\begin{array}{ll}
\frac{d^{2} u^{\prime}}{d x^{2}}+\left(\frac{F^{\prime}}{E I}\right) u^{\prime}=\frac{M_{A}^{\prime}}{E I}-\left(\frac{F^{\prime}}{E I}\right) y_{0}+\left(\frac{F_{T}}{2 E I}\right) x & 0 \leq x \leq \frac{L}{2} \\
\frac{d^{2} u^{\prime}}{d x^{2}}+\left(\frac{F^{\prime}}{E I}\right) u^{\prime}=\frac{M_{A}^{\prime}}{E I}-\left(\frac{F^{\prime}}{E I}\right) y_{0}-\left(\frac{F_{T}}{2 E I}\right)(L-x) & L / 2 \leq x \leq L .
\end{array}
$$

The variation of $u^{\prime}$ was symmetric about the midpoint. For $0 \leq x \leq L / 2$, it could be found by standard methods as:

$$
u^{\prime}(x)=C_{1}\left\{k^{\prime} x-\sin \left(k^{\prime} x\right)+\tan \left(\frac{k^{\prime} L}{4}\right)\left[\cos \left(k^{\prime} x\right)-1\right]\right\}+C_{0} \sin ^{2}\left(\frac{\pi x}{L}\right) .
$$

Here:

$$
C_{0}=H\left\{\frac{k \prime^{2} L^{2}}{4 \pi^{2}-k \prime^{2} L^{2}}\right\} \quad C_{1}=\frac{F_{T}}{2 k \prime^{3} E I} \quad k^{\prime}=\sqrt{F^{\prime} / E I} .
$$

The midpoint deflection $U^{\prime}=u^{\prime}(L / 2)$ was then:

$$
U^{\prime}=C_{1}\left\{\frac{k^{\prime} L}{2}-2 \tan \left(\frac{k^{\prime} L}{4}\right)\right\}+C_{0} .
$$


Now, to return $U^{\prime}$ to zero, we required a transverse force such that:

$$
C_{1}=\frac{C_{0}}{2 \tan \left(\frac{k^{\prime} L}{4}\right)-\frac{k^{\prime} L}{2}} .
$$

As $k^{\prime}$ was unknown, a further condition was required to determine $F_{T}$. This could be obtained from the compatibility. As the temperature was unchanged by the transverse force, we had $\Delta L^{\prime} / L=\Delta L / L$, where $\Delta L^{\prime} / L=1 / L \int_{0}^{L / 2}\left(\frac{d y^{\prime}}{d x}\right)^{2} d x$. To proceed, we started with the deflected shape:

$$
\frac{d y^{\prime}}{d x}=C_{1} k^{\prime}\left\{1-\cos \left(k^{\prime} x\right)-\tan \left(\frac{k^{\prime} L}{4}\right) \sin \left(k^{\prime} x\right)\right\}+\left(\frac{C_{2} \pi}{L}\right) \sin \left(\frac{2 \pi x}{L}\right) .
$$

Here, $C_{2}=H\left\{\frac{4 \pi^{2}}{4 \pi^{2}-k 2^{2} L^{2}}\right\}$. Consequently:

$$
\frac{d y^{\prime}}{d x}=C_{1} k^{\prime}\left\{1-\cos \left(k^{\prime} x\right)-\tan \left(\frac{k^{\prime} L}{4}\right) \sin \left(k^{\prime} x\right)\right\}+\left(\frac{C_{2} \pi}{L}\right) \sin \left(\frac{2 \pi x}{L}\right) .
$$

Using the above, the integral determining $\Delta L^{\prime}$ / $L$ could be evaluated, numerically or analytically. However, the expressions obtained in the latter case were non-linear in $k^{\prime}$. In each case, the values of $F_{T}$ and $F^{\prime}$ were, therefore, generally found by iteration to satisfy the conditions above for a given $F$. Figure 6 shows a typical result, where the initial shape $y_{0}(x)$, the actuated shape $y(x)$, and the centrally loaded shape $y^{\prime}(x)$ were plotted together for $k L=\pi$. The overall deflection increased as the actuator was driven, retaining a raised cosine shape; the midpoint deflection correctly returned to zero as the actuator was loaded.

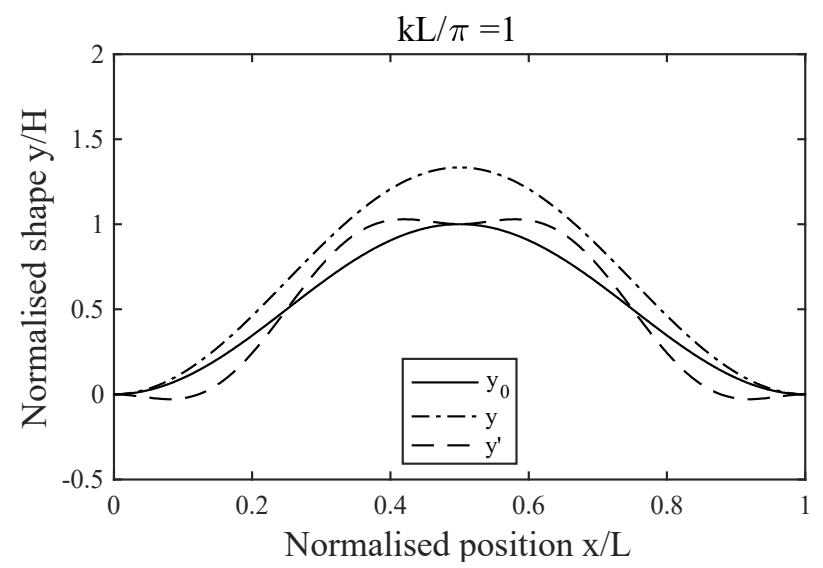

Figure 6. Initial, deflected, and centrally loaded beam shapes $y_{0}, y$, and $y^{\prime}$ of a raised cosine actuator for $k L / \pi=1$.

A simple analytic solution for the transverse stiffness could be obtained by assuming that $k^{\prime} L$ was small and by making power series approximations to Equation (40). This process yielded:

$$
\frac{d y^{\prime}}{d x} \approx C_{1} k^{\prime 3}\left\{\frac{x^{2}}{2}-\frac{L x}{4}\right\}+\left(\frac{C_{2} \pi}{L}\right) \sin \left(\frac{2 \pi x}{L}\right) .
$$

Squaring and integrating, we then obtained:

$$
\Delta L^{\prime} / L \approx-\frac{C_{1} C_{2} k^{\prime 3} L}{2 \pi^{2}}+\frac{C_{2}^{2} \pi^{2}}{4 L^{2}} .
$$


At a similar level of approximation, we had:

$$
\begin{array}{cc}
C_{0}=\frac{H k^{\prime 2} L^{2}}{4 \pi^{2}} & C_{1}=\frac{24 H}{\pi^{2} k^{\prime} L} \\
C_{2}=H\left\{1+\frac{k^{\prime 2} L^{2}}{4 \pi^{2}}\right\} & \frac{\Delta L}{L}=\left\{1+\frac{k^{2} L^{2}}{2 \pi^{2}}\right\}\left(\frac{\pi^{2} H^{2}}{4 L^{2}}\right) .
\end{array}
$$

A substitution into the compatibility condition then yielded an approximation for $k^{\prime}$ as:

$$
\frac{k \prime^{2}}{k^{2}}=\frac{1}{1-\frac{96}{\pi^{4}}} \approx 69 .
$$

Thus, the action of forcing the actuator back to its starting point increased $k^{\prime}$ significantly from the original value $k$ due to electrothermal actuation alone. To find the transverse stiffness, we noted that $F_{T}$ and $U$ could be approximated as:

$$
F_{T} \approx \frac{48 k^{\prime 2} E I H}{\pi^{2} L} \quad U \approx \frac{H k^{2} L^{2}}{4 \pi^{2}} .
$$

Consequently, the transverse stiffness $k_{T}=F_{T} / U$ could be extracted as:

$$
k_{T}=\left(\frac{k^{\prime 2}}{k^{2}}\right)\left(\frac{192 E I}{L^{3}}\right) \text {. }
$$

The term $k_{T 0}=192 E I / L^{3}$ was then the transverse stiffness of a straight, centrally loaded built-in beam. Shaping the beam and adding restraints at either end raised the stiffness by a factor of 69 , as shown above. More generally, the transverse stiffness could always be written in the form $k_{T}=\kappa k_{T 0}$, where $\kappa$ was a coefficient that depended on the initial value of $k$. Figure 7 shows the numerically calculated variation of $\kappa$ with $k L$. This fell monotonically from an initial value of 69 , implying that the actuator became weaker and weaker as it deflected.

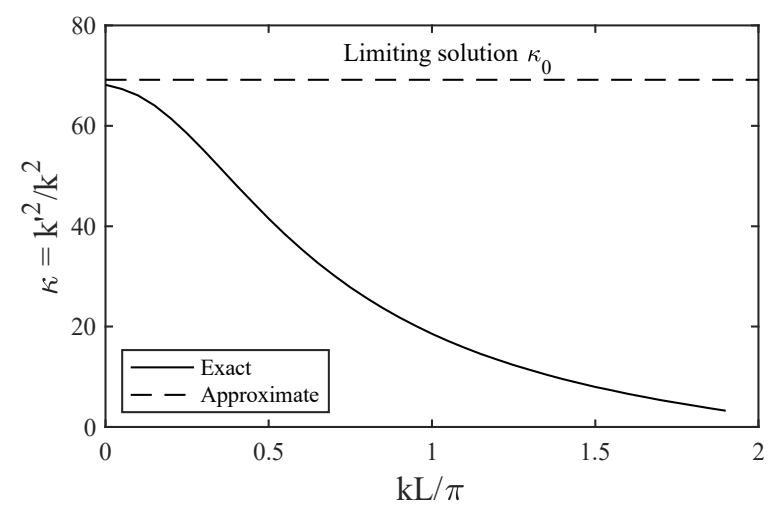

Figure 7. Variation of $\kappa=k \prime^{2} / k^{2}$ with $k L$ for a centrally loaded raised cosine actuator.

\section{Conclusions}

We presented analytic approximations to the results of the Euler theory that allowed the response of buckling-mode electrothermal actuators to be obtained in a closed-form, avoiding the need for an iterative solution of coupled analytic equations or a lengthy finite element analysis. The approximations were valid for actuators with very slender beams (such as NEMS designs) when the effects of bending dominated over those of axial compression. We compared the expressions with numerical solutions and showed them to be extremely accurate. We also presented higher-order corrections for less slender beams as found in MEMS actuators. 
The analysis focused on two specific actuator layouts based on V-beam and raised cosine beam shapes. Each had the same set of material parameters $\left(E, \alpha\right.$, and $\left.k_{t h}\right)$ and geometric design parameters $(W, L, D$, and $H)$. The careful choice of the latter allowed well-known trade-offs between drive power, frequency response, and mechanical stiffness but the closed form Equations (11) and (26) and the results in Figure 3 showed that there was little to choose between the two layouts for a fixed set of parameters. However, the approximation used (neglect of axial stress) may open the door to analytic design optimisation in more general cases; for example, when the beam width or other properties vary locally.

Author Contributions: Conceptualization, R.S. and D.L.; methodology, R.S.; formal analysis, R.S.; investigation, R.S. and D.L.; writing—original draft preparation, R.S.; writing-review and editing, D.L.; supervision, R.S.; All authors have read and agreed to the published version of the manuscript.

Funding: This research received no external funding.

Conflicts of Interest: The authors declare no conflict of interest.

\section{References}

1. Noworolski, J.M.; Klaassen, E.H.; Logan, J.R.; Petersen, K.E.; Maluf, N.I. Process for in-plane and out-of-plane single-crystal-silicon thermal microactuators. Sens. Actuators A 1996, 55, 65-69. [CrossRef]

2. Pan, C.S.; Hsu, W. An electro-thermally and laterally driven polysilicon microactuator. J. Micromech. Microeng. 1997, 7, 7-13. [CrossRef]

3. Comtois, J.H.; Michalecik, M.A.; Barron, C.C. Electrothermal actuators fabricated in four-level planarized surface micromachined polycrystalline silicon. Sens. Actuators A 1998, 70, 23-31. [CrossRef]

4. Cragun, R.; Howell, L.L. Linear thermomechanical actuators. In ASME International Mechanical Engineering Congress and Exposition; American Society of Mechanical Engineers: New York, NY, USA, 1999; Volume 16387, pp. 181-188. [CrossRef]

5. Que, L.; Park, J.; Gianchandani, Y. Bent-beam electrothermal actuators for high force applications. In Proceedings of the Technical Digest. In Proceedings of the IEEE International MEMS 99 Conference. Twelfth IEEE International Conference on Micro Electro Mechanical Systems, Orlando, FL, USA, 21 January 1999; pp. 31-36. [CrossRef]

6. Sinclair, M.J. A high force low area MEMS thermal actuator. In Proceedings of the ITHERM 2000. The Seventh Intersociety Conference on Thermal and Thermomechanical Phenomena in Electronic Systems, Las Vegas, NV, USA, 23-26 May 2000; pp. 127-132. [CrossRef]

7. Que, L.; Park, J.-S.; Gianchandani, Y.B. Bent-beam electrothermal actuators-Part I: Single-beam and cascaded devices. J. Microelectromech. Syst. 2001, 10, 247-254. [CrossRef]

8. Enikov, E.T.; Kedar, S.S.; Lazarov, K.V. Analytical model for analysis and design of V-shaped thermal microactuators. J. Microelectromech. Syst. 2005, 14, 788-798. [CrossRef]

9. Hoang, K.T.; Nguyen, D.T.; Pham, P.H. Impact of design parameters on working stability of the electrothermal V-shaped actuator. Microsyst. Technol. 2020, 26, 1479-1487. [CrossRef]

10. Hussein, H.; Fariborzi, H.; Younis, M.I. Modeling of beam electrothermal actuators. J. Microelectromech. Syst. 2020, $29,1570-1581$. [CrossRef]

11. Chen, H.; Wang, X.-J.; Wang, J.; Xi, Z.-W. Analysis of the dynamic behaviour of a V-shaped electrothermal microactuator. J. Micromech. Microeng. 2020, 30, 085005. [CrossRef]

12. Alcheikh, N.; Ouakad, H.M.; Younis, M.I. Dynamics of V-shaped electrothermal MEMS-based resonators. J. Microelectromech. Syst. 2020, 29, 1372-1381. [CrossRef]

13. Baracu, A.; Voicu, R.; Müller, R.; Avram, A.; Pustan, M.; Chiorean, R.; Birleanu, C.; Dodescu, C. Design and fabrication of a MEMS Chevron-type thermal actuator. AIP Conf. Proc. 2015, 25, 25-30. [CrossRef]

14. Shan, T.; Qi, X.; Cui, L.; Zhou, X. Thermal behaviour modelling and characteristics analysis of electrothermal microactuators. Microsyst. Technol. 2017, 23, 2629-2640. [CrossRef]

15. Thangavel, A.; Rengaswamy, R.; Sukumar, P.K.; Sekar, R. Modelling chevron electrothermal actuator and its performance analysis. Microsyst. Technol. 2018, 24, 1767-1774. [CrossRef]

16. Sciberras, T.; Demicoli, M.; Grech, I.; Mallia, B.; Mollicone, P.; Sammut, N. Coupled finite element-finite volume multi-physics analysis of MEMS electrothermal actuators. Micromachines 2022, 13, 8. [CrossRef]

17. Vangbo, M. An analytical analysis of a compressed bistable buckled beam. Sens. Actuators A 1998, 69, 212-216. [CrossRef]

18. Qiu, J.; Lang, H.; Slocum, A.H. A curved-beam bistable mechanism. J. Microelectromech. Syst. 2004, 13, 137-146. [CrossRef]

19. Park, S.; Hah, D. Pre-shaped buckled beam actuators: Theory and experiments. Sens. Actuators A 2008, 148, 186-192. [CrossRef]

20. Lott, C.D.; McLain, T.W.; Harb, J.N.; Howell, L.L. Modeling the thermal behaviour of a surface micromachined linear-displacement thermomechanical microactuator. Sens. Actuators A 2002, 101, 239-250. [CrossRef] 
21. Hickey, R.; Sameoto, D.; Hubbard, T.; Kujath, M. Time and frequency response of two-arm micromachined thermal actuators. J. Micromech. Microeng. 2003, 13, 40. [CrossRef]

22. Zhu, Y.; Reza Moheimani, S.O.; Yuce, M.R. Bidirectional electrothermal actuator with Z-shaped beams. IEEE Sens. J. 2012, 12, 2508-2509. [CrossRef]

23. Zhang, Z.; Zhang, W.; Wu, Q.; Yu, Y.; Liu, X.; Zhang, X. Closed-form modelling and design analysis of V- and Z-shaped electrothermal microactuators. J. Micromech. Microeng. 2017, 27, 015023. [CrossRef]

24. Zhang, Z.; Yu, Y.; Liu, X.; Zhang, X. Dynamic modelling and analysis of V- and Z-shaped electrothermal microactuators. Microsyst. Technol. 2017, 23, 3775-3789. [CrossRef]

25. Chu, L.L.; Hetrick, J.A.; Gianchandani, Y.B. High amplification compliant micro-transmissions for rectilinear electrothermal actuators. Sens. Actuators A 2002, 97-98, 776-783. [CrossRef]

26. Zhang, Y.; Huang, Q.-A.; Li, R.-G.; Li, W. Macro-modeling for polysilicon cascaded bent beam electrothermal microactuators Sens. Actuators A 2006, 128, 165-175. [CrossRef]

27. Hubbard, N.B.; Howell, L.L. Design and characterization of a dual-stage, thermally actuated nanopositioner. J. Micromech Microeng. 2005, 15, 1482-1493. [CrossRef]

28. Shen, X.; Chen, X. Mechanical performance of a cascaded V-shaped electrothermal actuator. J. Adv. Robot. Syst. 2013, 10, 379. [CrossRef]

29. Alcheikh, N.; Hajjaj, A.Z.; Jaber, N.; Younis, M.I. Electrothermally actuated tunable clamped-guided resonant microbeams. Mech Syst. Signal Process. 2018, 98, 1069-1076. [CrossRef]

30. Varona, J.; Tecpoyotl-Torres, M. Design of MEMS vertical-horizontal chevron thermal actuators. Sens. Actuators A 2009, 153, 127-130. [CrossRef]

31. Sassen, W.P.; Henneken, V.A.; Tichem, M.; Sarro, P.M. Contoured V-beam actuator with improved temperature uniformity. Sens. Actuators A 2008, 144, 341-347. [CrossRef]

32. Kwan, A.M.H.; Song, S.; Lu, X.; Lu, L.; Teh, Y.K.; Teh, Y.F.; Chong, E.W.C.; Gao, Y.; Hau, W.; Zeng, F.; et al. Improved designs for an electrothermal in-plane microactuator. J. Microelectromech. Syst. 2012, 21, 587-595. [CrossRef]

33. Wittwer, J.W.; Baker, M.S.; Howell, L.L. Simulation, measurement, and asymmetric buckling of thermal microactuators. Sens. Actuators A 2006, 128, 395-401. [CrossRef]

34. Chu, L.L.; Gianchandani, Y.B. A micromachined 2D positioner with electrothermal actuation and sub-nanometer capacitive sensing. J. Micromech. Microeng. 2003, 13, 279-285. [CrossRef]

35. Messenger, R.K.; Aten, Q.T.; McLain, T.W.; Howell, L.L. Piezoresistive feedback control of a MEMS thermal actuator. J. Microelectromech. Syst. 2009, 18, 1267-1278. [CrossRef]

36. Park, J.; Chu, L.L.; Oliver, A.D.; Gianchandani, Y.B. Bent-beam electrothermal actuators-Part II: Linear and rotary microengines. J. Microelectromech. Syst. 2001, 10, 255-262. [CrossRef]

37. Maloney, J.M.; Schreiber, D.S.; DeVoe, D.L. Large force electrothermal linear micromotors. J. Micromech. Microeng. 2004, 14, 226-234. [CrossRef]

38. Brown, M.; Hubbard, T.; Kujath, M. Development of a long-range untethered frictional microcrawler. J. Micromech. Microeng. 2007, 17, 1025-1033. [CrossRef]

39. Geisberger, A.; Kadylak, D.; Ellis, M. A silicon electrothermal rotational micro motor measuring one cubic millimeter. J. Micromech Microeng. 2006, 16, 1943-1950. [CrossRef]

40. Wang, Y.; Li, Z.; McCormick, D.T.; Tien, N.C. A micromachined RF microrelay with electrothermal actuation. Sens. Actuators A 2003, 103, 231-236. [CrossRef]

41. Wang, Y.; McCormick, D.T.; Tien, N.C. A low-voltage lateral MEMS switch with high RF performance. J. Microelectromech. Syst. 2004, 13, 902-911. [CrossRef]

42. Syms, R.R.A.; Zou, H.; Stagg, J. Robust latching MEMS translation stages for micro-optical systems. J. Micromech. Microeng. 2004, 14, 667-674. [CrossRef]

43. Unamuno, A.; Yao, J.; Uttamchandani, D. Alignment and fixing of fiber optics based on electrothermal MEMS actuators. IEEE Photon. Tech. Lett. 2005, 17, 816-818. [CrossRef]

44. Syms, R.R.A.; Zou, H.; Stagg, J. MOEMS alignment stages with Vernier latch mechanisms. J. Opt. A: Pure Appl. Opt. 2006, 8, S305-S312. [CrossRef]

45. Henneken, V.A.; Tichem, M.; Sarro, P.M. In-package MEMS-based thermal actuators for micro-assembly. J. Micromech. Microeng. 2006, 16, S107-S115. [CrossRef]

46. Sinclair, M. 1D and 2D scanning mirrors using thermal buckle-beam actuation. Proc. SPIE 2001, 4592, 307-314. [CrossRef]

47. Syms, R.R.A.; Zou, H.; Stagg, J.; Veladi, H. Sliding-blade MEMS iris and variable optical attenuator. J. Micromech. Microeng. 2004, 14, 1700-1710. [CrossRef]

48. Unamuno, A.; Uttamchandani, D. MEMS variable optical attenuator with vernier latching mechanism. IEEE Photon. Tech. Lett. 2006, 18, 88-90. [CrossRef]

49. Sameoto, D.; Hubbard, T.; Kujath, M. Operation of electrothermal and electrostatic MUMPS microactuators underwater. J. Micromech. Microeng. 2004, 14, 1359-1366. [CrossRef]

50. Zhang, W.; Gnerlich, M.; Paly, J.J.; Sun, Y.; Jing, G.; Voloshin, A.; Tatic-Lucic, S. A polymer V-shaped electrothermal actuator array for biological applications. J. Micromech. Microeng. 2008, 18, 075020. [CrossRef] 
51. Holst, G.L.; Jensen, B.D. A silicon thermomechanical in-plane microactuation system for large displacements in aqueous environments. In ASME International Mechanical Engineering Congress and Exposition; American Society of Mechanical Engineers: New York, NY, USA, 2011; Volume 54976, pp. 491-502. [CrossRef]

52. Muthuswamy, J.; Okandon, M.; Giletti, A.; Baker, M.S.; Jain, T. An array of microactuated electrodes for monitoring of singleneuronal activity in rodents. IEEE Trans. Biomed. Eng. 2005, 52, 1470-1477. [CrossRef]

53. Jackson, N.; Sridharan, A.; Anand, S.; Baker, M.; Okandan, M.; Muthuswamy, J. Long-term neural recordings using MEMS-based movable microelectrodes in the brain. Front. Neuroeng. 2010, 3, 10. [CrossRef] [PubMed]

54. Potekhina, A.; Wang, C. Review of electrothermal actuators and applications. Actuators 2019, 8, 69. [CrossRef]

55. Liu, D.; Syms, R.R.A. NEMS by sidewall transfer lithography. IEEE J. Microelectromech. Syst. 2014, 23, 1366-1373. [CrossRef]

56. Allen, H.G.; Bulson, P.S. Background to Buckling; McGraw-Hill Book Company (UK) Ltd.: Maidenhead, UK, 1980. Available online: http:/ / worldcat.org/isbn/0070841004 (accessed on 9 January 2022). 